\title{
Extracellular vesicles as mediators of the progression and chemoresistance of pancreatic cancer and their potential clinical applications
}

\author{
Jiangdong Qiu ${ }^{1 \dagger} \mathbb{D}$, Gang Yang ${ }^{1 \dagger}$, Mengyu Feng ${ }^{1}$, Suli Zheng ${ }^{1}$, Zhe Cao ${ }^{1}$, Lei You', Lianfang Zheng ${ }^{2}$, \\ Taiping Zhang ${ }^{1,3^{*}}$ and Yupei Zhao ${ }^{1 *}$
}

\begin{abstract}
Pancreatic cancer is one of the most lethal cancers worldwide due to its insidious symptoms, early metastasis, and chemoresistance. Hence, the underlying mechanisms contributing to pancreatic cancer progression require further exploration. Based on accumulating evidence, extracellular vesicles, including exosomes and microvesicles, play a crucial role in pancreatic cancer progression and chemoresistance. Furthermore, they also possess the potential to be promising biomarkers, therapy targets and tools for treating pancreatic cancer. Therefore, in-depth studies on the role of extracellular vesicles in pancreatic cancer are meaningful. In this review, we focus on the regulatory effects of extracellular vesicles on pancreatic cancer progression, metastasis, cancer-related immunity and chemoresistance, particularly their potential roles as biomarkers and therapeutic targets.
\end{abstract}

Keywords: Extracellular vesicles, Pancreatic cancer, Chemoresistance, Clinical applications

\section{Background}

Pancreatic ductal adenocarcinoma (PDAC, hereafter referred to as pancreatic cancer [PC]) is the seventh most common malignancy, ranking as the fourth and sixth leading causes of cancer-related death in the USA and China, respectively. Patients with $\mathrm{PC}$ have a 5-year survival rate of approximately $6 \%$ and a median survival rate of 6 months [1-3]. PC is expected to become the second leading cause of cancer-related death in the USA by 2030 [4]. The dismal prognosis of $\mathrm{PC}$ is mainly attributed to poor detection rates at early stages, rapid progression and disappointing surgical resection outcomes. Most patients with PC lack diagnostic symptoms during early stages, and the existing screening biomarkers, such as CA19-9, are not sufficient for a highly sensitive and specific diagnosis of PC [5]. When a patient is diagnosed with localized $\mathrm{PC}$, surgical resection is

\footnotetext{
*Correspondence: tpingzhang@yahoo.com; zhao8028@263.net

${ }^{\dagger}$ Equal contributors

'Department of General Surgery, Peking Union Medical College Hospital, Chinese Academy of Medical Sciences and Peking Union Medical College, No. 1 Shuaifuyuan, Wangfujing Street, Beijing 100730, China

Full list of author information is available at the end of the article
}

regarded as the only potential curative treatment [6]. However, patients should expect only a 5-year survival rate of 23-26\% before recurrence [7]. Unfortunately, approximately $80 \%$ of patients have reached an unresectable stage at the time of diagnosis. Chemotherapy with gemcitabine is an indispensable treatment for these patients. However, the effectiveness of chemotherapeutic drugs is often plagued by chemoresistance, worsening the outcomes of patients with metastatic disease $[8,9]$. Thus, a better understanding of the underlying cellular and molecular mechanisms of PC progression and chemoresistance is urgently needed.

Extracellular vesicles (EVs), which were considered containers of cellular debris, have recently been highlighted as intercellular communication tools and mechanisms of molecular transfer [10-12]. EVs include exosomes, ectosomes, microvesicles, apoptotic bodies and oncosomes, according to their sizes and biogenesis mechanisms [13]. Many types of cells have the capacity to secrete EVs, including dendritic cells (DCs) [14], B and T cells [15], neurons [16], fibroblasts [17], stem cells [18], and cancer cells [19]. EVs are also detected in and isolated from multiple 
biological fluids, such as blood, urine, ascitic fluid, saliva and supernatants [20, 21]. EV-mediated intercellular communication is achieved by biologically active substances, such as proteins and nucleic acids, carried by EVs. Similarly, the interactions between cells and the tumor microenvironment are also partially mediated by EVs [22]. EVs have been shown to play an important role in the tumorigenesis, progression, metastasis and chemoresistance of various malignancies, such as breast cancer [23], hepatocellular carcinoma [24] and prostate cancer [25]. The functions of EVs in PC have also been investigated [26]. In this review, we will discuss the roles of EVs in the progression, metastasis and chemoresistance of PC as well as their promising applications as biomarkers and therapeutic targets in PC.

\section{Biological features of PC-derived EVs}

\section{Morphology, biogenesis and secretion of EVs}

Exosomes and microvesicles (MVs) are two main subtypes of EVs, with diameters of 30-120 nm and 120$1000 \mathrm{~nm}$, respectively. Exosomes, which are typically composed of a lipid bilayer membrane surrounding a small cytosol lacking cellular organelles, were first described by Johnstone RM in 1987 during the in vitro culture of sheep reticulocytes [11, 12]. Exosomes are usually cup/disk-shaped and originate from a late endosome following inward budding of multivesicular bodies (MVBs), whereas MVs are irregularly shaped and directly formed by cell membrane shedding $[27,28]$. The intraluminal vesicles (ILVs) budding from MVBs are the original forms of exosomes. Three independent pathways are involved in exosomal biogenesis: the endosomal sorting complex required for the transport (ESCRT)dependent pathway and the ceramide-dependent pathway contribute to the formation of ILVs. Inhibition of the two pathways decreases exosomal biogenesis and secretion. While the tetraspanin-dependent pathway is responsible for selecting cargoes for exosomes [29, 30]. Exosome secretion is mediated by RAB GTPase proteins which control intracellular vesicles trafficking and docking to plasma membrane, and soluble NSF-attachment protein receptor (SNARE) complexes which allow fusion of lipid bilayer $[30,31]$. Increasing intracellular $\mathrm{Ca}^{2+}$, lower $\mathrm{pH}$ in microenvironment, up-regulation of P53 protein and heparanase stimulate exosomes secretion [32-34]. Besides, the EVs released by cancer cells can be triggered by anti-cancer therapy, questioning the longterm efficacy of such treatment because EVs may promote PC progression as discussed in the context [35]. Three mechanisms are currently reported to be involved in exosome uptake by receipt cells: (1) an interaction between a surface receptor and ligand, (2) internalization through direct fusion, and (3) internalization through endocytosis [36-38].
Several methods, such as ultracentrifugation, affinity isolation, size exclusion chromatography and membrane filtration, have been applied to isolate EVs from conditioned cell culture medium and body fluids. But most published studies of EVs have employed ultracentrifugation, the "Gold Standard" for EV isolation [11]. The International Society for Extracellular Vesicles (ISEV) has provided authoritative guidance for EV isolation and purification [39]. EV detection can be realized by transmission electron microscopy (for direct imaging) and Western blotting or flow cytometry (for EV markers analysis) [40-42]. The markers used for exosome analysis include tetraspanins (including CD9, CD63, CD81, and CD82), ESCRT-associated proteins (including tumor susceptibility gene 101 (TSG101) and apoptosis-linked gene 2-interacting protein X (ALIX)), cytoplasmic proteins (heat shock protein 70 (HSP70) and HSP90), adhesion molecules (integrins), and membrane transport and fusion proteins (annexins) [30, 43, 44].

\section{Role of EVs in PC}

The histology of $\mathrm{PC}$ is characterized by a complex microenvironment consisting of PC cells and other components including vascular endothelial cells, immune cells, fibroblasts, myofibroblasts, stellate cells and extracellular matrix(ECM). Cancer-associated fibroblasts (CAFs) promote remodeling of ECM and tumor growth. Immune cells in the microenvironment of PC have a highly immunosuppressive composition and further contribute to immune evasion [45]. The interactions between cancer cells and the tumor microenvironment are crucial steps in tumor progression [46-48], contributing to the altered metabolism and hyper-proliferation of cancer cells as well as tumor metastasis and abnormal tumor-associated immunity $[46,49,50]$. The role of EVs in PC is illustrated by these interactions across this part because these interactions are partially modulated by EVs. For example, EVs from fibroblasts promote invasive behavior and upregulate drug resistance pathways in cancer cells, whereas EVs from tumor cells reprogram normal fibroblasts into CAFs [51-53]. Here, we describe the following functions of EVs in PC: (1) regulating the proliferation of PC cells, (2) promoting PC invasion and metastasis, and (3) modulating tumor-associated immunity. Figure 1 summarizes the functions of EVs in PC.

\section{EVs regulate $\mathrm{PC}$ cell proliferation}

EVs play different roles in regulating PC cell proliferation, depending on their origin. In vitro studies, exosomes released from gemcitabine-treated CAFs increased the proliferation and survival of both chemosensitive and chemoresistant PC cell lines. It was partially attributed to the increased level of Snail and its target, miR-146a, in recipient cells. Inhibition of exosome secretion from CAFs 


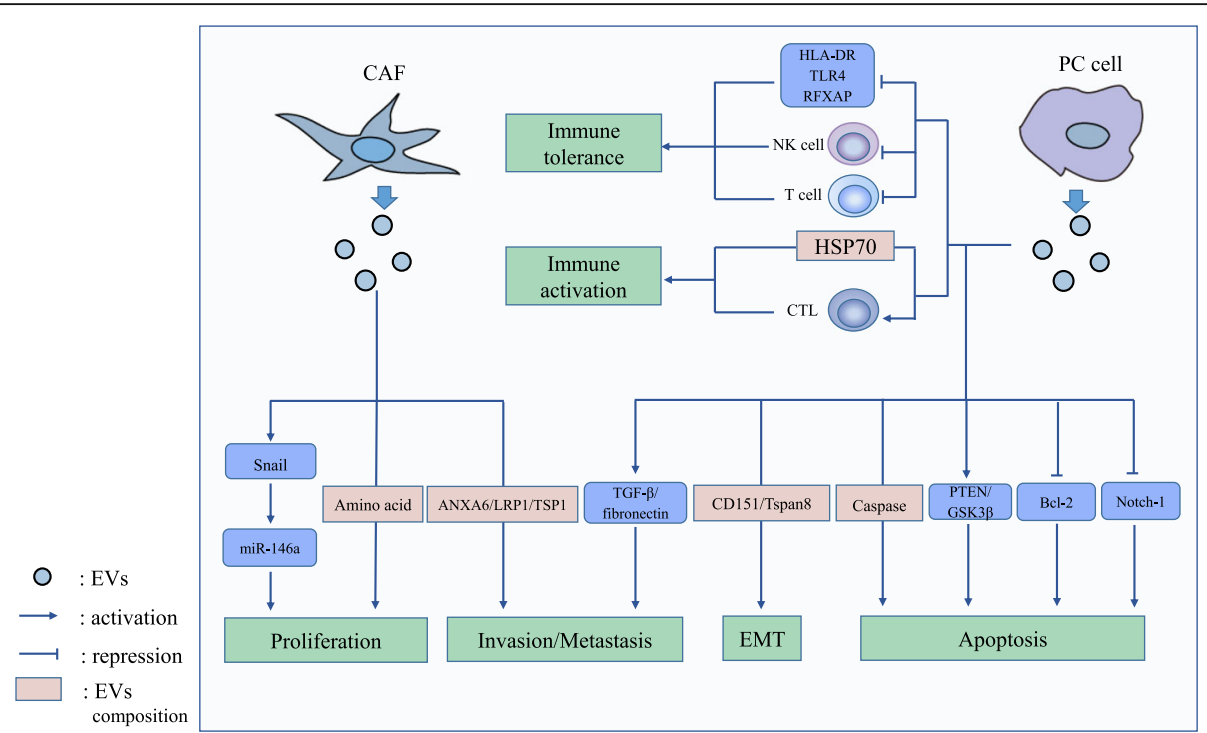

Fig. 1 The functions of EVs in PC. The regulatory effects of EVs on cell proliferation, metastasis, and tumor-associated immunity are shown

reduced PC cell proliferation and survival [54]. Furthermore, CAF-derived exosomes (CDEs) rescued the proliferation of nutrient-deprived $\mathrm{BxPC} 3$ and $\mathrm{MiaPaCa}-2$ cells by supplying them with metabolites in a KRAS-independent manner. This effect was blocked by heparin, an inhibitor of receptor-mediated endocytosis [49]. However, EVs isolated from PC cells (SOJ-6) supernatant downregulated PC cells proliferation by activating phosphatase and tensin homolog (PTEN) and glycogen synthase kinase 3 beta (GSK-3 $\beta$ ), thus evoking the mitochondria-dependent apoptotic pathway [55]. Decreased expression of hairy and enhancer-of-split homolog-1 (HES-1), the intranuclear target of the Notch-1 signaling pathway, also promoted the EV-induced suppression of PC cells proliferation [56]. These in vitro studies indicate EVs with different origins exert opposite effects on PC cell proliferation, which requires further elucidation. Although circulating EVs from healthy people's serum have been approved to induce apoptosis in PC cells [57], further in vivo studies are needed to assess the effects of EVs on PC cells proliferation and tumor growth, which may indicate a possible intervention method for PC therapy.

\section{EVs promote PC cell invasion and metastasis}

EVs modulate PC invasion and metastasis because of their regulatory effects on PC cells and the tumor microenvironment. EVs derived from pancreatic stellate cells (PSCs) and enhanced the migration of PC cells, which were decreased by an exosome inhibitor [58]. CAFderived annexin 6A-positive (ANXA6+) EVs containing the annexin A6/LDL receptor-related protein 1/thrombospondin1 (ANXA6/LRP1/TSP1) complex increased PC aggressiveness following uptake by PC cells, and ANXA6 depletion via infection of shANXA6 in CAFs impaired tumor metastasis [59]. EVs with in vivo origins from malignant effusions of colorectal cancer, breast cancer and small lung cancer induced PC cell migration [60]. Another in vivo study found that EVs derived from PC cells contributed to the formation of the premetastasis niche in the liver [3]. In this study, PCderived exosomes expressing high levels of macrophage migration inhibitory factor (MIF) fused with Kupffer cells, activated fibrotic pathways and created a proinflammatory environment. These changes supported metastasis by upregulating the expression of transforming growth factor $\beta$ (TGF- $\beta$ ) and fibronectin as well as recruiting bone-marrow-derived cells (macrophages and neutrophils) to the liver [3]. Furthermore, the formation of a pre-metastasis niche by exosomes required the help of CD44v6 [61], a cancer-initiating cell (CIC) marker, to provide a soluble matrix in vivo and enable exosomes to transfer migratory and invasive capacity to non-CICs [61-63]. Moreover, the epithelial-mesenchymal transition (EMT) is supported by CD151-/tetraspanin 8competent exosomes, which drives the differentiation of non-metastatic PC cells toward a motile phenotype [64]. Taken together, EVs derived from tumor cells or other cellular components of the tumor microenvironment indeed play a positive role in PC invasion and metastasis, with the assistance of different molecules.

\section{EVs modulate tumor-associated immunity}

Cancer is characterized by impaired immune surveillance and tolerance toward cancer cells. The pancreatic tumor microenvironment is immunosuppressive because of inhibitory cytokines and recruitment of immunomodulatory cells like myeloid-derived suppressor cells (MDSCs) which suppress T-cell activation via TGF $\beta[45,65]$. Besides, B 
cells, tumor-associated macrophages (TAMs), and Tregs also play immunosuppressive roles in TME of PC by suppressing the function of cytotoxic T cells (CTLs) and CD8 ${ }^{+} \mathrm{T}$ cells [45]. EVs have recently been shown to play a pivotal but contradictory role in PC immunity. On one hand, EVs derived from PC cells or immune cells induce immune elimination. On the other hand, some PC-derived EVs captured by immune cells circumvent the immune response. For instance, exosomes derived from the ASML cell line inhibit the proliferation of leukocytes and reduce $\mathrm{T}$ cell migration, whereas they support the activation of effector lymphocytes, such as CTLs [66]. Exosomes released from cancer cells induced monocyte survival in the tumor microenvironment by regulating the mitogen-activated protein kinase (MAPK) pathway, resulting in the continuous generation of TAMs [67]. Besides, PC-derived exosomes suppress the immune system by downregulating human leukocyte antigen D related (HLA-DR) expression in monocytes and the tumor-killing capacity of natural killer (NK) cells $[68,69]$. Furthermore, miR-203 and miR212-3p are also involved in immune tolerance caused by PC-derived exosomes via decreasing the expression of toll-like receptor 4 (TLR4) and regulatory factor Xassociated protein (RFXAP) in DCs [70, 71]. In contrast, the exosomal proteins with miRNA depleted via miRNA lysis and ultrafiltration activate DCs/cytokine-induced killer (CIK) cells to target PC [72]. HSP70 surfacepositive exosomes derived from $\mathrm{PC}$ cells promote the migration and cytolytic activity of NK cells [73]. Overall, the pro- or anti-effects of EVs on tumor-associated immunity depend on differences in the EV composition and target cells, but these different functions of EVs may contribute to investigations of the use of modified EVs as a possible tumor vaccine.

\section{EVs participate in the formation of chemoresistance in PC}

Currently, chemotherapy is an indispensable treatment option for patients with advanced pancreatic cancer. Several clinical trials have shown that adjuvant chemotherapy based on fluorouracil and gemcitabine (GEM) improved survival in patients with resected PC [74, 75]. A randomized phase III trial has proven that the noninferiority of oral S-1, a fluoropyrimidine derivative had a higher 2-year overall survival than GEM in adjuvant chemotherapy [76]. For metastatic PC, chemotherapy includes GEM monotherapy or GEM plus novel regimens, such as erlotinib [77] and nanoparticle albumin-bound paclitaxel [78]. Besides, the FOLFIRINOX regimen which consists of oxaliplatin, folinic acid (leucovorin), irinotecan, bolus fluorouracil, and infusional fluorouracil has better chemotherapy response than GEM monotherapy in metastatic PC [79]. Unfortunately, however, chemoresistance occurs in most cases after long-term exposure to chemotherapeutics, particularly GEM, the standard chemotherapeutic agent for unresectable pancreatic cancer. Based on accumulating evidence, EVs may play a role as intercellular communicators in promoting chemoresistance in multiple cancers, including leukemia [80], glioblastoma [81], lung cancer [82], gastric cancer [83], breast cancer [84], prostate cancer [25], ovarian cancer [85] and PC [9]. The mechanisms underlying the EV-mediated chemoresistance in cancers include transferring the drug-resistance-related gene multidrug resistant-1 (MDR-1), P glycoprotein [86], survivin [87] and ubiquitin carboxyl terminal hydrolase-L1 [84] to recipient cells.

The effects of EVs on PC chemoresistance partially rely on the RNA it transfers. When incubated with GEM, PC cells upregulated the expression of miR-155, which was transferred to other PC cells via exosomes. MiR-155 contributed to resistance among PC cells via anti-apoptosis pathways and suppression of deoxycytidine kinase (dCK), a key gemcitabine-metabolizing enzyme $[9,88]$. Furthermore, miR-155 overexpression upregulated the synthesis and secretion of exosomes and miR-155 contents in exosomes [9], which formed a positive loop in regulating GEM resistance. The positive role of EVs in transporting RNA among cancer cells to induce resistance has also been observed in breast and lung cancers $[82,89]$.

In addition, EVs conferred chemoresistance to PC cells by promoting ROS detoxification through increases in the expression of the ROS detoxifying genes superoxide dismutase 2 (SOD2) and catalase (CAT) [88]. Moreover, CAFs, which were intrinsically resistant, play an active role in GEM resistance by increasing EV release upon exposure to GEM, leading to the upregulation of chemoresistance-inducing factor Snail in recipient PC cells [54]. The expression of Snail and its target, miR146a, were also upregulated in GEM-treated CAF-derived EVs [54], which may partially explained the increase in Snail expression in recipient cells. GEM increases Snail expression in PC cells [90]; therefore, CAF-derived EVs may increase Snail expression in recipient cells by transferring GEM or its metabolite to PC cells at a dose that is not sufficient to induce cytotoxicity but induces resistance. In the tumor microenvironment, miR-21 derived from macrophages and CAFs are also transferred to cancer cells via EVs, inducing chemoresistance by activating the phosphoinositol 3-kinase (PI3K)/AKT signaling pathway or binding apoptotic peptidase activating factor 1 (APAF1) [83, 85]. Taken together, EVs from PC cells or other cell types in the tumor microenvironment facilitate chemoresistance by regulating RNAs, proteins, relevant genes and signaling pathways, and extensive investigations are required to further explain EVrelated chemoresistance in PC. 


\section{EVs as diagnostic and prognostic biomarkers of PC}

Due to the non-specific symptoms in early stages, most patients (approximately 80-85\%) are diagnosed with metastatic or locally advanced PC at the initial examination [91, 92]. Patients who are diagnosed incidentally during medical examinations have a better prognosis than patients with evident symptoms, and patients with PC diameters smaller than $10 \mathrm{~mm}$ can expect a 5-year survival rate of $80.4 \%$ [93, 94]. Therefore, methods for the early detection of PC are urgently needed to improve the overall survival of patients with PC. Currently, the most widely used and the only FDA-approved biomarker for PC is CA19-9. However, CA19-9 is not optimal for PC screening because of its relatively low sensitivity and specificity (70-90\% and $68-91 \%$, respectively) [95]; it is therefore primarily used to monitor progression and the therapeutic response [94]. More importantly, 5\%-10\% of the population are Lewis antigen negative and unable to produce CA19-9 [94]. Hence, it is urgent to find new biomarkers. The ideal biomarkers for PC should detect the initial lesions at early stage with high sensitivity and specificity, differentiating PC with healthy ones and benign pancreatic diseases. Besides, they should be able to predict progression and prognosis, contributing to more effective therapy managements. Up to now, extensive investigations have been conducted to identify EVs as novel biomarkers for PC. Because EVs contain specific molecules of original cells, and display stability and abundance in various biological fluids [96], which may lead to a higher sensitivity and specificity in PC diagnosis. Compositions of EVs cover most cancer cellassociated biomarkers, including proteins, mRNAs, miRNAs, and DNA [97]. Proteins and miRNAs are the focus of EV biomarker research.

EVs used for biomarker detection are usually isolated from blood. Researchers applied RT-PCR to analyze the exosomal miRNAs extracted from the blood of 22 individuals with PC (9 at early stage and 13 at advanced stage) and 27 individuals without PC (6 with ampullary carcinoma, 7 with benign pancreatic tumors, 6 with chronic pancreatitis and 8 healthy participants) and assess the roles of four miRNAs (miR-17-5p, miR-21, miR155 and miR-196a) as biomarkers of PC [98]. Levels of miR-17-5p and miR-21 were elevated in patients with PC, with sensitivity and specificity values of $72.7 \%$ and 92.6\% and $95.5 \%$ and $81.5 \%$, respectively. MiR-17-5p expression was elevated in metastasis and advanced PC, indicating that it was a potential biomarker for unresectable PC [98]. Similar results were reported in the investigations of miR-550 [99] and miR-10b [100], which displayed increased levels in exosomes isolated from the plasma of patients with PC and conditioned media from PC cell lines, suggesting that they may serve as early biomarkers in PC diagnosis.
In addition to miRNAs, EV proteins play a significant role in PC diagnosis. MIF was expressed at high level in plasma exosomes isolated from PC mouse models with liver metastasis compared with healthy ones. Besides, the increased MIF level was also present in mice with PanIN lesions, suggesting that it might serve as a biomarker for early diagnosis and predicting liver metastasis [3]. In 2015, Nature published an article presenting a near-perfect diagnostic biomarker for PC - glypican-1 (GPC1) - a cell surface proteoglycan that is specifically enriched on cancer cell-derived exosomes [101]. GPC1 ${ }^{+}$ circulating exosomes were significantly elevated in patients with PC (including carcinoma-in-situ, stage I-IV) compared to healthy individuals, indicating that it may act as an biomarker for all stages of PC and aid in distinguishing $\mathrm{PC}$ from benign pancreatic disease and healthy individuals, while CA 19-9 levels in the serum fail to distinguish patients with PC from those with benign pancreatic disease. The sensitivity and specificity of GPC1+ circulating exosomes in diagnosing PC were both $100 \%$ [101]. Furthermore, the $\mathrm{GPC}^{+}$exosome level reflected the tumor burden and distant metastasis, and a reduction in the number of $\mathrm{GPC}^{+}$exosomes was related to increased survival [101]. Interestingly, however, another study indicated that high levels of exosomal miR-10b, miR-21, miR-30c, and miR-181a and low levels of miR-let7a differentiated PC from normal control and chronic pancreatitis samples, while GPC1 level was not significantly different between normal, PC and chronic pancreatitis samples [102]. The difference may be explained by different sample volumes, or different antibodies for GPC1. Except for single EV biomarker, investigators utilized a combination of exosomal proteins and serum/exosomal miRNAs to diagnose PC [103]. In this study, the exosomal protein markers included CD44v6, TSPAN8, epithelial cell adhesion molecule (EpCAM), MET, and CD104, whereas miR-1246, miR-4644, miR3976, and miR-4306 were selected as exosomal miRNA markers. Concomitant evaluation of these markers exhibited a sensitivity of 1.00 (confidence interval (CI) 0.95-1) and specificity of 0.80 (CI 0.67-0.90) for PC compared with all other groups and a sensitivity of 0.93 (CI $0.81-$ 0.98) when non-PC-malignancies were excluded [103].

In addition to plasma/serum biomarkers, salivary biomarkers have shown potential in diagnosing PC, possibly because miRNA expression profiles in saliva are similar to those in serum [104]. In the study including 12 pancreatobiliary tract cancer patients and 13 healthy donors, salivary exosomal miR-1246 and miR-4644 exhibit great potential as pancreatobiliary tract cancer early biomarkers [105]. Besides, Salivary exosomal proteins are also utilized for the detection of PC.[107]Thus, tests of salivary EV-derived miRNAs and proteins may be a novel method for diagnosing $\mathrm{PC}$. 
The extraction of EV biomarkers from body fluids typically requires multiple ultracentrifugation steps, which are time consuming. Several investigators have proposed new technologies to simplify this process. A microfluidic-based platform to isolate circulating exosomes comprised an ExoChip with an antibody against CD63 to capture exosomes and a standard plate-reader for subsequent exosome quantification [107]. An ultrasensitive localized surface plasmon resonance (LSPR)-based microRNA sensor with single nucleotide specificity was developed to quantify microRNA-10b levels, which are elevated in exosomes from the plasma of patients with PC [100]. In addition, another novel microfluidics-based approach was presented by researchers from the University of Notre Dame. This platform consisted of surface acoustic wave (SAW) exosome lysis and ion-exchange nanomembrane RNA sensing performed concurrently on two separate chips; this platform has the advantages of a shorter analysis time ( $1.5 \mathrm{~h}$ for the total analysis), smaller sample volumes $(100 \mu \mathrm{L})$, and reduced sample loss [99]. Table 1 summarizes the current diagnostic biomarkers for PC.

Majority of these studies included both patients with benign pancreatic diseases and healthy individuals as controls to assess the role of EV biomarkers for PC diagnosis, and various EV biomarkers proved to indicate disease progression and predict prognosis. However, further studies on EVs biomarkers need to be conducted to assess response to therapy, such as chemotherapy and radiotherapy. Besides, several obstacles remain to be overcome before the clinical application of EVs as biomarkers: prolonged EV isolation procedures, unavailability of specific markers to separate tumor cell-derived EVs from normal cell-derived EVs and lack of sensitive system for large cohorts of clinical samples.

\section{Potential applications of EVs in treating PC}

An increasing number of studies has aimed to apply EVs to PC therapy. The roles of EVs in PC treatment in these studies are divided into three categories: (1) tumorassociated immunity stimulators, (2) drug carriers and (3) therapeutic targets.

\section{EVs as tumor-associated immunity stimulators}

EVs released by tumor cells are known to facilitate immune suppression and tolerance toward cancer cells, thus promoting cancer progression. However, EVs might act as a promising immunity stimulator against tumors. EVs secreted by human DCs induced the activation of

Table 1 EVs biomarkers for pancreatic cancer diagnosis

\begin{tabular}{|c|c|c|c|c|}
\hline Biomarker & Sample & Sensitivity and specificity & Methods & Reference \\
\hline miR-17-5p, miR-21 & $\begin{array}{l}\text { Serum: } 22 \text { PCs, } 6 \text { benign pancreatic } \\
\text { tumors, } 7 \text { ampullary carcinomas, } 6 \\
\text { CPs, } 8 \text { healthy donors }\end{array}$ & $\begin{array}{l}72.7 \% \text { and } 92.6 \% \text { for miR- } \\
17-5 p 95.5 \% \text { and } 81.5 \% \\
\text { for miR-21 }\end{array}$ & $\begin{array}{l}\text { Ultracentrifugation for } \\
\text { exosome isolation; RT-PCR for } \\
\text { miRNA screening }\end{array}$ & [98] \\
\hline miR-550 & Media from the PANC1 cell line & Not mentioned & $\begin{array}{l}\text { SAW for exosomes lysis; ion- } \\
\text { exchange nanomembrane } \\
\text { sensor for miRNA detection }\end{array}$ & [99] \\
\hline miR-10b & $\begin{array}{l}\text { Plasma:3 PCs, } 3 \text { CPs, } 3 \text { healthy } \\
\text { donors }\end{array}$ & Not mentioned & $\begin{array}{l}\text { Ultracentrifugation for exosome } \\
\text { isolation; LSPR-Based sensor for } \\
\text { miRNA quantification }\end{array}$ & [100] \\
\hline $\begin{array}{l}\text { miR-10b, miR-21, miR-30c, } \\
\text { miR-181a, miR-let7a }\end{array}$ & $\begin{array}{l}\text { Blood:29 PCs, } 11 \text { CPs, } 6 \text { normal } \\
\text { donors }\end{array}$ & $\begin{array}{l}\text { Sensitivity: } 100 \% \text { Specificity: } \\
\text { 100\% For all these biomarkers }\end{array}$ & $\begin{array}{l}\text { Ultracentrifugation for exosome } \\
\text { isolation; RT-qPCR for miRNA } \\
\text { detection }\end{array}$ & [102] \\
\hline $\begin{array}{l}\text { miR-1246, miR-4644, miR-3976, } \\
\text { miR-4306 and CD44v6,Tspan8, } \\
\text { EpCAM, MET, CD104 }\end{array}$ & $\begin{array}{l}\text { Serum: } 131 \text { PCs, } 25 \text { CPs, } 22 \text { benign } \\
\text { pancreatic tumors, } 12 \text { non-PCs, } 30 \\
\text { healthy donors }\end{array}$ & $\begin{array}{l}\text { Sensitivity:100\% Specificity:80\% } \\
\text { With 93\% for excluding non- } \\
\text { Pa-malignancies }\end{array}$ & $\begin{array}{l}\text { Ultracentrifugation for exosome } \\
\text { isolation; RT-PCR for miRNA } \\
\text { detection; flow-cytometry for } \\
\text { protein analysis }\end{array}$ & [103] \\
\hline miR-1246, miR-4644 & $\begin{array}{l}\text { saliva: } 12 \text { pancreatobiliary tract } \\
\text { cancer patients, } 13 \text { healthy donors }\end{array}$ & $\begin{array}{l}66.7 \% \text { and } 100 \% \text { for miR- } 1246 \\
75.0 \% \text { and } 76.9 \% \text { for miR-4644 }\end{array}$ & $\begin{array}{l}\text { Total Exosome Isolation } \\
\text { Reagent for exosoems isolation; } \\
\text { RT-qPCR for miRNA detection }\end{array}$ & [105] \\
\hline $\begin{array}{l}\text { Apbblip, Aspn, BCO31781, Daf2, } \\
\text { Foxp1, Gng2,Incenp }\end{array}$ & $\begin{array}{l}\text { Salivary glands from PC mouse } \\
\text { model }\end{array}$ & Not mentioned & $\begin{array}{l}\text { Ultracentrifugation for exosome } \\
\text { isolation; Western-blotting for } \\
\text { protein anaysis }\end{array}$ & [106] \\
\hline MIF & $\begin{array}{l}\text { Plasma: } 5 \text { mice with PanIN, } 8 \text { mice } \\
\text { with PC, } 6 \text { heallthy mice }\end{array}$ & Not mentioned & $\begin{array}{l}\text { ultracentrifugation for exosome } \\
\text { isolation; ELISA for MIF } \\
\text { measurement }\end{array}$ & [3] \\
\hline Glypican-1 & $\begin{array}{l}\text { Serum: } 32 \text { breast cancer, } 190 \text { PCs, } \\
100 \text { healthy donor }\end{array}$ & Sensitivity:100\% Specificity:100\% & $\begin{array}{l}\text { Ultracentrifugation for exosome } \\
\text { isolation;ultraperformance liquid } \\
\text { chromatography-mass } \\
\text { spectrometry(UPLC-MS) for } \\
\text { protein evaluation }\end{array}$ & [101] \\
\hline
\end{tabular}


$\mathrm{CD}^{+} \mathrm{T}$ cells in vitro [108]. Researchers enhanced the immune activity of exosomes isolated from cultured PANC-1 cell supernatants by depleting exosomal miRNAs via lysis and ultrafiltration. Notably, miRNAdepleted exosome proteins increased the tumor-killing capacity of $\mathrm{DC} / \mathrm{CIK}$ toward $\mathrm{PC}$ cells, suggesting that modified PC cell-derived exosomes may be a potential immunotherapeutic approach for PC [72]. In addition to $\mathrm{PC}$, tumor cell-derived EVs also induce anti-tumor immune activity in lymphoma [109], hepatocellular carcinoma [110], and colorectal cancer [111]. Furthermore, some clinical trials have confirmed that cancer progression may be halted by EV-associated immunotherapy $[111,112]$.

\section{EVs as drug carriers}

EVs carry multiple biological substances and are captured by recipient cells, indicating that they may be an ideal drug delivery tool. Unlike synthetic nanoparticle drug delivery systems, EVs harbor transmembrane or membrane-anchored proteins to enhance endocytosis, which promotes the delivery of their contents $[113,114]$. After priming with paclitaxel, mesenchymal stromal cells
(MSCs) substantially inhibited the proliferation of the CFPAC-1 pancreatic cell line by secreting EVs containing paclitaxel into the conditioned medium [115]. EVs also deliver curcumin, a turmeric root derivative, to recipient PC cells to promote cytotoxicity in vitro [116]. In addition to common chemotherapeutics, EVs could transport RNA and proteins into recipient cells. According to a newly published article, exosomes that had been engineered to convey a siRNA or short hairpin RNA targeting oncogenic KRAS ${ }^{\mathrm{G} 12 \mathrm{D}}$, a common mutation in $\mathrm{PC}$, suppressed cancer in mouse models and significantly increased overall survival [117]. Similarly, the delivery of exosomes carrying the survivin T34A mutant, a survivin blocker, to the MiaPaCa-2 cell line increases gemcitabine sensitivity in PC cells [118]. A novel compound comprising exosomes and staphylococcal enterotoxin B (EXO/ $\mathrm{SEB}$ ) induces the apoptosis of pancreatic cell lines and increases the expression of BAX, BAK and FAS [119]. The advantage of exosomes over liposomes in drug delivery may depend on CD47, a widely expressed integrin-associated transmembrane protein that protects exosomes from clearance by monocytes by binding to CD47 and signal regulatory protein alpha (SIRP $\alpha)$ [117].

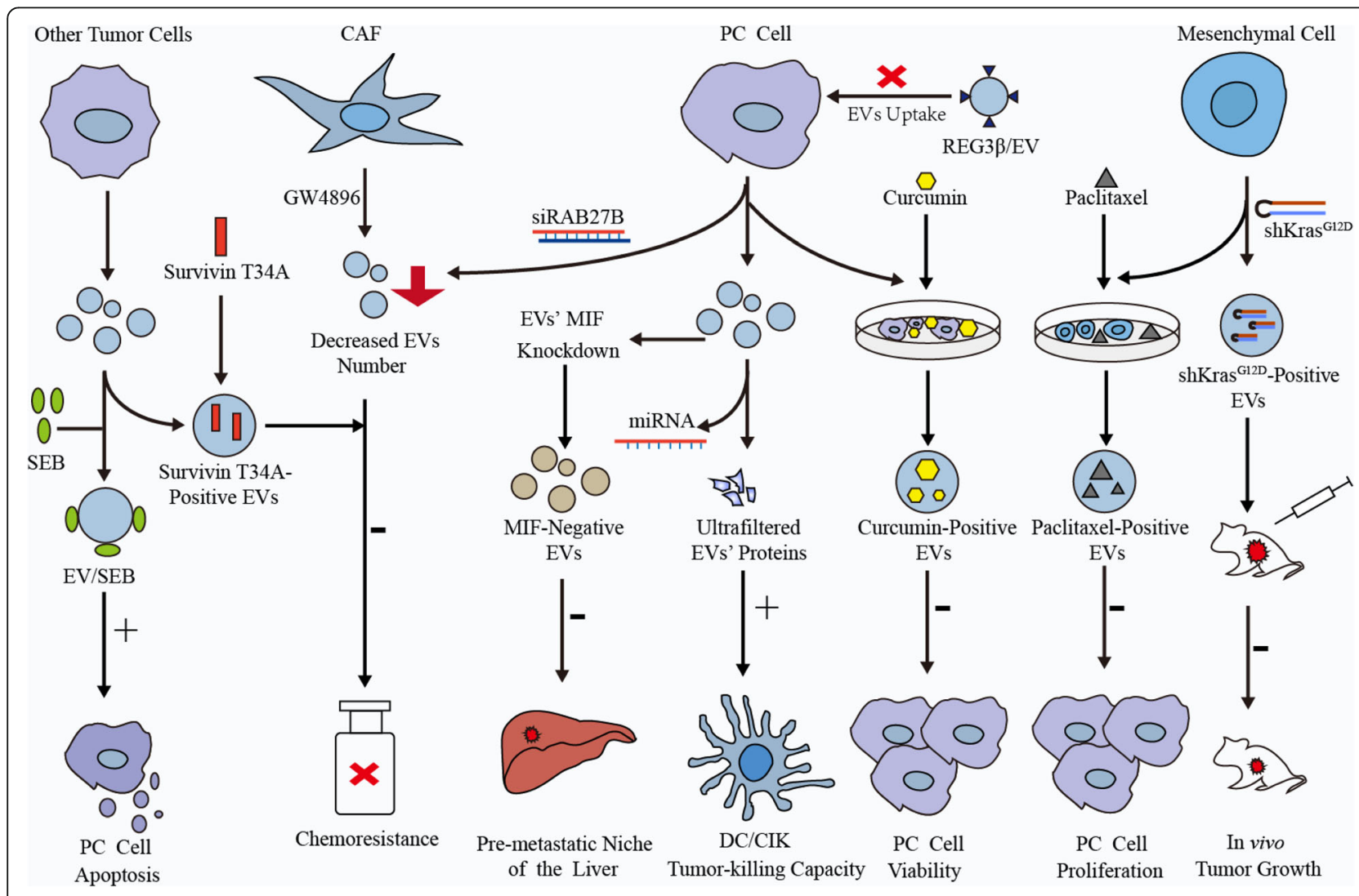

Fig. 2 The functions of EVs in PC therapeutic intervention. The potential applications of EVs with different origins in PC therapeutic interventions are shown 


\section{EVs as a therapeutic target}

As discussed above, EV secretion plays a pivotal role in PC progression and chemoresistance. Thus, strategies that block EV secretion from specific cell types like CAFs or tumor cells may be a potential treatment for PC. The formation of the pre-metastatic niche in the liver was abolished by the silencing of exosomal MIF [3]. Moreover, the chemoresistance of PC cells transferred by GEM-exposed CAFs was eliminated by GW4869, an inhibitor of exosome release, significantly reducing the survival of PC cells [54]. MiR-155-induced GEM resistance was ameliorated by decreasing the number of exosomes following siRAB27B transfection in PC cells [9]. In addition to suppressing $\mathrm{EV}$ secretion, inhibition of $\mathrm{EV}$ uptake may be another strategy in PC treatment. REG3 $\beta$, a lectin that binds to EV surface, released by the normal pancreatic tissues surrounding tumor impaired the uptake of EVs by tumor cells both in vitro and vivo and inhibited the migration and metabolic changes in cancer cells [120]. All of these studies indicate that EVs may be a potential therapeutic target for the treatment of PC. However, as discussed above, EVs released by different cell types may present pro- or anti- tumor effects. How to block the EV secretion or uptake by specific cell types like CAFs or tumor cells at the exclusion of other cell subsets in tumor microenvironment remains a challenge to overcome. Figure 2 summarizes the functions of EVs in PC therapeutic intervention.

\section{Conclusions}

EVs have various roles in modulating PC progression, chemoresistance, diagnosis and treatment. The underlying mechanisms remain to be further explored, particularly the seemingly contradictory effects of EVs on tumor cell proliferation and tumor-associated immunity. Biomarkers related to exosomes prove to be promising in diagnosing $\mathrm{PC}$ and determining patient prognosis; further investigations are required to explore the potential clinical applications of EVs, which may usher in a new era for PC treatment.

\footnotetext{
Abbreviations

APAF1: Apoptotic peptidase activating factor 1; CAFs: Cancer-associated fibroblasts; CDEs: CAF-derived exosomes; CIC: Cancer-initiating cell; CIK cells: Cytokine-induced killer cells; CTLs: Cytotoxic T cells; dCK: deoxycytidine kinase; DCs: Dendritic cells; EMT: Epithelial-mesenchymal transition; EpCAM: Adhesion molecule; ESCRT: Endosomal sorting complex required for the transport; EVs: Extracellular vesicles; GEM: Gemcitabine; GPC1: Glypican-1; GSK-3ß: Glycogen synthase kinase 3 beta; HES-1: Hairy and enhancer-of-split homolog-1; HLA-DR: Human leukocyte antigen D related; ISEV: The International Society for Extracellular Vesicles; LSPR: Localized surface plasmon resonance; MAPK: Mitogen-activated protein kinase; MDR1: Multidrug resistant-1; MDSCs: Myeloid-derived suppressor cells; MIF: Migration inhibitory factor; MSCs: Mesenchymal stromal cells; MVBs: Multivesicular bodies; MVs: Microvesicles; NK cells: Natural killer cells; PC: Pancreatic cancer; PDAC: Pancreatic ductal adenocarcinoma; PI3K: Phosphoinositol 3-kinase; PSCs: Pancreatic stellate cells; PTEN: Phosphatase and tensin homolog; RFXAP: Regulatory factor X-
}

associated protein; SAW: Surface acoustic wave; SIRPa: Signal regulatory protein alpha; SNARE: Soluble NSF-attachment protein receptor;

SOD2: Superoxide dismutase 2; TAMs: Tumor-associated macrophages; TGF$\beta$ : Transforming growth factor $\beta$; TLR4: Toll-like receptor 4

\section{Acknowledgements \\ The authors acknowledge the contribution of all investigators at the participating study sites.}

\section{Funding}

This study was supported by grants from the National Natural Science Foundation of China (No. 81472327), the Major State Basic Research Development Program of China (973 Program, No. 2014CB542300), the National Science and Technology Support Program of China (No. 2014BAl09B11), the Chinese Academy Medical Science Innovation Fund for Medical Sciences (No. 2016-I2M-1-001) and PUMC Youth Fund and the Fundamental Research Funds for Central Universities (No. 2017320027).

\section{Availability of data and materials}

Not applicable

\section{Authors' contributions}

TZ and YZ contributed to study conception and design, JQ and GY wrote the main manuscript text, and MF, SZ and ZC prepared the figures and Tables. LY and LZ provided advice regarding the paper. All authors reviewed the manuscript. All authors read and approved the final manuscript.

\section{Ethics approval and consent to participate}

Not applicable

\section{Consent for publication}

Not applicable

\section{Competing interests}

The authors declare that they have no competing interests.

\section{Publisher's Note}

Springer Nature remains neutral with regard to jurisdictional claims in published maps and institutional affiliations.

\section{Author details}

${ }^{1}$ Department of General Surgery, Peking Union Medical College Hospital, Chinese Academy of Medical Sciences and Peking Union Medical College, No. 1 Shuaifuyuan, Wangfujing Street, Beijing 100730, China. ${ }^{2}$ Department of Nuclear Medicine, Peking Union Medical College Hospital, Chinese Academy of Medical Sciences and Peking Union Medical College, Beijing 100730, China. ${ }^{3}$ Clinical Immunology Center, Chinese Academy of Medical Sciences and Peking Union Medical College, Beijing 100730, China.

Received: 12 August 2017 Accepted: 27 December 2017

Published online: 05 January 2018

\section{References}

1. Siegel RL, Miller KD, Jemal A. Cancer statistics, 2016. CA Cancer J Clin. 2016; 66:7-30.

2. Chen W, Zheng R, Baade PD, Zhang S, Zeng H, Bray F, Jemal A, XQ Y, He J. Cancer statistics in China, 2015. CA Cancer J Clin. 2016:66:115-32.

3. Costa-Silva B, Aiello NM, Ocean AJ, Singh S, Zhang H, Thakur BK, Becker A, Hoshino A, Mark MT, Molina H, Xiang J, Zhang T, Theilen TM, et al. Pancreatic cancer exosomes initiate pre-metastatic niche formation in the liver. Nat Cell Biol. 2015;17:816-26.

4. Kamisawa T, Wood LD, Itoi T, Takaori K. Pancreatic cancer. Lancet. 2016;388: 73-85.

5. Nuzhat Z, Kinhal V, Sharma S, Rice GE, Joshi V, Salomon C. Tumour-derived exosomes as a signature of pancreatic cancer - liquid biopsies as indicators of tumour progression. Oncotarget. 2017;8:17279-91.

6. Ryan DP, Hong TS, Bardeesy N. Pancreatic adenocarcinoma. N Engl J Med. 2014:371:1039-49.

7. Matsushita H, Yang YM, Pandol SJ, Seki E. Exosome migration inhibitory factor as a marker and therapeutic target for pancreatic cancer. Gastroenterology. 2016;150:1033-5. 
8 Xiong G, Feng M, Yang G, Zheng S, Song X, Cao Z, You L, Zheng L, Hu Y, Zhang T, Zhao Y. The underlying mechanisms of non-coding RNAs in the chemoresistance of pancreatic cancer. Cancer Lett. 2017;397:94-102.

9 Mikamori M, Yamada D, Equchi H, Hasegawa S, Kishimoto T, Tomimaru Y, Asaoka T, Noda T, Wada H, Kawamoto K, Gotoh K, Takeda Y, Tanemura M, et al. MicroRNA-155 controls exosome synthesis and promotes gemcitabine resistance in pancreatic ductal adenocarcinoma. Sci Rep. 2017;7:42339.

10 Valadi H, Ekstrom K, Bossios A, Sjostrand M, Lee JJ, Lotvall JO. Exosomemediated transfer of mRNAs and microRNAs is a novel mechanism of genetic exchange between cells. Nat Cell Biol. 2007;9:654-9.

11 Min L, Shen J, Tu C, Hornicek F, Duan Z. The roles and implications of exosomes in sarcoma. Cancer Metastasis Rev. 2016;35:377-90.

12 Johnstone RM, Adam M, Hammond JR, Orr L, Turbide C. Vesicle formation during reticulocyte maturation. Association of plasma membrane activities with released vesicles (exosomes). J Biol Chem. 1987;262:9412-20.

13 Lotvall J, Hill AF, Hochberg F, Buzas El, Di Vizio D, Gardiner C, Gho YS, Kurochkin IV, Mathivanan S, Quesenberry P, Sahoo S, Tahara H, Wauben MH, et al. Minimal experimental requirements for definition of extracellular vesicles and their functions: a position statement from the International Society for Extracellular Vesicles. J Extracell Vesicles. 2014;3:26913.

14 Silva AM, Almeida MI, Teixeira JH, Maia AF, Calin GA, Barbosa MA, Santos SG. Dendritic cell-derived extracellular vesicles mediate mesenchymal stem/ stromal cell recruitment. Sci Rep. 2017;7:1667.

15 Mazzeo C, Calvo V, Alonso R, Merida I, Izquierdo M. Protein kinase D1/2 is involved in the maturation of multivesicular bodies and secretion of exosomes in T and B lymphocytes. Cell Death Differ. 2016;23:99-109.

16 Von Bartheld CS, Altick AL. Multivesicular bodies in neurons: distribution, protein content, and trafficking functions. Prog Neurobiol. 2011;93:313-40.

17 Donnarumma E, Fiore D, Nappa M, Roscigno G, Adamo A, laboni M, Russo V, Affinito A, Puoti I, Quintavalle C, Rienzo A, Piscuoglio S, Thomas R, et al. Cancer-associated fibroblasts release exosomal microRNAs that dictate an aggressive phenotype in breast cancer. Oncotarget. 2017;8:19592-608.

18 Burrello J, Monticone S, Gai C, Gomez Y, Kholia S, Camussi G. Stem cellderived extracellular vesicles and immune-modulation. Front Cell Dev Biol. 2016;4:83.

19 Li Y, Yang Y, Xiong A, Wu X, Xie J, Han S, Zhao S. Comparative gene expression analysis of lymphocytes treated with exosomes derived from ovarian cancer and ovarian cysts. Front Immunol. 2017;8:607.

20 Wei M, Yang T, Chen X, Wu Y, Deng X, He W, Yang J, Wang Z. Malignant ascitesderived exosomes promote proliferation and induce carcinoma-associated fibroblasts transition in peritoneal mesothelial cells. Oncotarget. 2017;

21 ELA S, Mager I, Breakefield XO, Wood MJ. Extracellular vesicles: biology and emerging therapeutic opportunities. Nat Rev Drug Discov. 2013;12:347-57.

22 O'Driscoll L. Expanding on exosomes and ectosomes in cancer. N Engl J Med. 2015:372:2359-62.

23 CY W, SL D, Zhang J, Liang AL, Liu YJ. Exosomes and breast cancer: a comprehensive review of novel therapeutic strategies from diagnosis to treatment. Cancer Gene Ther. 2017;24:6-12.

24 Yang N, Li S, Li G, Zhang S, Tang X, Ni S, Jian X, Xu C, Zhu J, Lu M. The role of extracellular vesicles in mediating progression, metastasis and potential treatment of hepatocellular carcinoma. Oncotarget. 2017;8:3683-95.

25 Li J, Yang X, Guan H, Mizokami A, Keller ET, Xu X, Liu X, Tan J, Hu L, Lu Y, Zhang J. Exosome-derived microRNAs contribute to prostate cancer chemoresistance. Int J Oncol. 2016:49:838-46.

26 Jin $\mathrm{H}, \mathrm{Wu}$ Y, Tan $\mathrm{X}$. The role of pancreatic cancer-derived exosomes in cancer progress and their potential application as biomarkers. Clin Trans Oncol. 2017:19(8):921-30

27 Webber J, Yeung V, Clayton A. Extracellular vesicles as modulators of the cancer microenvironment. Semin Cell Dev Biol. 2015:40:27-34.

28 Nedaeinia R, Manian M, Jazayeri MH, Ranjbar M, Salehi R, Sharifi M, Mohaghegh F, Goli M, Jahednia SH, Avan A, Ghayour-Mobarhan M. Circulating exosomes and exosomal microRNAs as biomarkers in gastrointestinal cancer. Cancer Gene Ther. 2017;24:48-56.

29 Raposo G, Stoorvogel W. Extracellular vesicles: exosomes, microvesicles, and friends. J Cell Biol. 2013;200:373-83.

30 Kowal J, Tkach M, Thery C. Biogenesis and secretion of exosomes. Curr Opin Cell Biol. 2014;29:116-25.

31 Gross JC, Chaudhary V, Bartscherer K, Boutros M. Active Wnt proteins are secreted on exosomes. Nat Cell Biol. 2012;14:1036-45.

32 Savina A, Furlan M, Vidal M, Colombo MI. Exosome release is regulated by a calcium-dependent mechanism in K562 cells. J Biol Chem. 2003;278:20083-90.
33 Li J, Yu J, Liu A, Wang Y. Retraction notice to "ss-elemene against human lung cancer via up-regulation of P53 protein expression to promote the release of exosome": LUNG 86/2 (2014) 144-150. Lung Cancer. 2016;96:120.

34 Thompson CA, Purushothaman A, Ramani VC, Vlodavsky I, Sanderson RD. Heparanase regulates secretion, composition, and function of tumor cellderived exosomes. J Biol Chem. 2013;288:10093-9.

35 Aubertin K, Silva AK, Luciani N, Espinosa A, Djemat A, Charue D, Gallet F, Blanc-Brude O, Wilhelm C. Massive release of extracellular vesicles from cancer cells after photodynamic treatment or chemotherapy. Sci Rep. 2016; 6:35376.

36 Tian T, Wang Y, Wang H, Zhu Z, Xiao Z. Visualizing of the cellular uptake and intracellular trafficking of exosomes by live-cell microscopy. J Cell Biochem. 2010:111:488-96.

37 Feng D, Zhao WL, Ye YY, Bai XC, Liu RQ, Chang LF, Zhou Q, Sui SF. Cellular internalization of exosomes occurs through phagocytosis. Traffic. 2010;11:675-87.

38 Escrevente C, Keller S, Altevogt P, Costa J. Interaction and uptake of exosomes by ovarian cancer cells. BMC Cancer. 2011:11:108.

39 Witwer KW, Buzas El, Bemis LT, Bora A, Lasser C, Lotvall J, Nolte-'t Hoen EN, Piper MG, Sivaraman S, Skog J, Thery C, Wauben MH, Hochberg F. Standardization of sample collection, isolation and analysis methods in extracellular vesicle research. J Extracell Vesicles. 2013:2:1-25.

40 Xu R, Greening DW, Zhu HJ, Takahashi N, Simpson RJ. Extracellular vesicle isolation and characterization: toward clinical application. J Clin Invest. 2016; 126:1152-62.

41 Ko J, Carpenter E, Issadore D. Detection and isolation of circulating exosomes and microvesicles for cancer monitoring and diagnostics using micro-/nano-based devices. Analyst. 2016;141:450-60.

42 Erdbrugger U, Lannigan J. Analytical challenges of extracellular vesicle detection: a comparison of different techniques. Cytometry A. 2016;89:123-34.

43 Vlassov AV, Magdaleno S, Setterquist R, Conrad R. Exosomes: current knowledge of their composition, biological functions, and diagnostic and therapeutic potentials. Biochim Biophys Acta. 1820;2012:940-8.

44 Liang B, Peng P, Chen S, Li L, Zhang M, Cao D, Yang J, Li H, Gui T, Li X, Shen K. Characterization and proteomic analysis of ovarian cancer-derived exosomes. J Proteome. 2013;80:171-82.

45 Zhan HX, Zhou B, Cheng YG, JW X, Wang L, Zhang GY, Crosstalk HSY. Between stromal cells and cancer cells in pancreatic cancer: new insights into stromal biology. Cancer Lett. 2017:392:83-93.

46 Whiteside TL. The tumor microenvironment and its role in promoting tumor growth. Oncogene. 2008;27:5904-12.

47 Allinen M, Beroukhim R, Cai L, Brennan C, Lahti-Domenici J, Huang H, Porter D, Hu M, Chin L, Richardson A, Schnitt S, Sellers WR, Polyak K. Molecular characterization of the tumor microenvironment in breast cancer. Cancer Cell. 2004;6:17-32

48 Fiaschi T, Chiarugi P. Oxidative stress, tumor microenvironment, and metabolic reprogramming: a diabolic liaison. Int J Cell Biol. 2012;2012:762825.

49 Zhao H, Yang L, Baddour J, Achreja A, Bernard V, Moss T, Marini JC, Tudawe T, Seviour EG, San Lucas FA, Alvarez H, Gupta S, Maiti SN, et al. Tumor microenvironment derived exosomes pleiotropically modulate cancer cell metabolism. elife. 2016;5:e10250.

50 Brauer HA, Makowski L, Hoadley KA, Casbas-Hernandez P, Lang LJ, RomanPerez E, D'Arcy M, Freemerman AJ, Perou CM, Troester MA. Impact of tumor microenvironment and epithelial phenotypes on metabolism in breast cancer. Clin Cancer Res. 2013;19:571-85.

51 Luga V, Zhang L, Viloria-Petit AM, Ogunjimi AA, Inanlou MR, Chiu E, Buchanan M, Hosein AN, Basik M, Wrana JL. Exosomes mediate stromal mobilization of autocrine Wnt-PCP signaling in breast cancer cell migration. Cell. 2012;151:1542-56

52 Boelens MC, TJ W, Nabet BY, Xu B, Qiu Y, Yoon T, Azzam DJ, Twyman-Saint Victor C, Wiemann BZ, Ishwaran H, Ter Brugge PJ, Jonkers J, Slingerland J, et al. Exosome transfer from stromal to breast cancer cells regulates therapy resistance pathways. Cell. 2014;159:499-513.

53 Pang W, Su J, Wang Y, Feng H, Dai X, Yuan Y, Chen X, Yao W. Pancreatic cancer-secreted miR-155 implicates in the conversion from normal fibroblasts to cancer-associated fibroblasts. Cancer Sci. 2015;106:1362-9.

54 Richards KE, Zeleniak AE, Fishel ML, Wu J, Littlepage LE, Hill R. Cancerassociated fibroblast exosomes regulate survival and proliferation of pancreatic cancer cells. Oncogene. 2017;36:1770-8.

55 Ristorcelli E, Beraud E, Verrando P, Villard C, Lafitte D, Sbarra V, Lombardo D, Verine A. Human tumor nanoparticles induce apoptosis of pancreatic cancer cells. FASEB J. 2008;22:3358-69. 
56 Ristorcelli E, Beraud E, Mathieu S, Lombardo D, Verine A. Essential role of notch signaling in apoptosis of human pancreatic tumoral cells mediated by exosomal nanoparticles. Int J Cancer. 2009;125:1016-26.

57 Schneider J, Chromik AM, UhI W, Mugge A, Bulut D. Apoptosis in esophagus and pancreas carcinoma cells induced by circulating microparticles is related to phosphatidyl serine and microparticle-associated caspases. Med Oncol. 2012;29:962-9.

58 Takikawa T, Masamune A, Yoshida N, Hamada S, Kogure T, Shimosegawa T. Exosomes derived from pancreatic stellate cells: MicroRNA signature and effects on pancreatic cancer cells. Pancreas. 2017;46:19-27.

59 Leca J, Martinez S, Lac S, Nigri J, Secq V, Rubis M, Bressy C, Serge A, Lavaut MN, Dusetti N, Loncle C, Roques J, Pietrasz D, et al. Cancer-associated fibroblast-derived annexin A6+ extracellular vesicles support pancreatic cancer aggressiveness. J Clin Invest. 2016;126:4140-56.

60 Gamperl H, Plattfaut C, Freund A, Quecke T, Theophil F, Gieseler F. Extracellular vesicles from malignant effusions induce tumor cell migration: inhibitory effect of LMWH tinzaparin. Cell Biol Int. 2016;40:1050-61.

61 Jung T, Castellana D, Klingbeil P, Hernández IC, Vitacolonna M, Orlicky DJ, Roffler SR, Brodt P, Zöller M. CD44v6 dependence of Premetastatic niche preparation by exosomes. Neoplasia. 2009;11:1093-IN17.

62 Wang Z, Von Au A, Schnolzer M, Hackert T, Zoller M. CD44v6-competent tumor exosomes promote motility, invasion and cancer-initiating cell marker expression in pancreatic and colorectal cancer cells. Oncotarget. 2016;7:55409-36.

63 Heiler S, Wang Z, Zoller M. Pancreatic cancer stem cell markers and exosomes - the incentive push. World J Gastroenterol. 2016;22:5971-6007.

64 Yue S, Mu W, Erb U, Zoller M. The tetraspanins CD151 and Tspan8 are essential exosome components for the crosstalk between cancer initiating cells and their surrounding. Oncotarget. 2015;6:2366-84.

65 Waghray M, Yalamanchili M, di Magliano MP, Simeone DM. Deciphering the role of stroma in pancreatic cancer. Curr Opin Gastroenterol. 2013;29:53743.

66 Zech D, Rana S, Buchler MW, Zoller M. Tumor-exosomes and leukocyte activation: an ambivalent crosstalk. Cell Commun Signal. 2012;10:37.

67 Song X, Ding Y, Liu G, Yang X, Zhao R, Zhang Y, Zhao X, Anderson GJ, Nie $\mathrm{G}$. Cancer cell-derived exosomes induce mitogen-activated protein kinasedependent monocyte survival by transport of functional receptor tyrosine kinases. J Biol Chem. 2016;291:8453-64.

68 Javeed N, Gustafson MP, Dutta SK, Lin Y, Bamlet WR, Oberg AL, Petersen GM, Chari ST, Dietz AB, Mukhopadhyay D. Immunosuppressive CD14+HLADRlo/neg monocytes are elevated in pancreatic cancer and "primed" by tumor-derived exosomes. Oncoimmunology 2017; 6: e1252013.

69 Katsiougiannis S, Chia D, Kim Y, Singh RP, Wong DT. Saliva exosomes from pancreatic tumor-bearing mice modulate NK cell phenotype and antitumor cytotoxicity. FASEB J. 2017;31:998-1010.

70 Ding G, Zhou L, Qian Y, Fu M, Chen J, Chen J, Xiang J, Wu Z, Jiang G, Cao L. Pancreatic cancer-derived exosomes transfer miRNAs to dendritic cells and inhibit RFXAP expression via miR-212-3p. Oncotarget. 2015;6:29877-88.

71 Zhou M, Chen J, Zhou L, Chen W, Ding G, Cao L. Pancreatic cancer derived exosomes regulate the expression of TLR4 in dendritic cells via miR-203. Cell Immunol. 2014;292:65-9.

72 Que RS, Lin C, Ding GP, Wu ZR, Cao LP. Increasing the immune activity of exosomes: the effect of miRNA-depleted exosome proteins on activating dendritic cell/cytokine-induced killer cells against pancreatic cancer. J Zhejiang Univ Sci B. 2016;17:352-60.

73 Gastpar R, Gehrmann M, Bausero MA, Asea A, Gross C, Schroeder JA, Multhoff $\mathrm{G}$. Heat shock protein 70 surface-positive tumor exosomes stimulate migratory and cytolytic activity of natural killer cells. Cancer Res. 2005;65:5238-47.

74 Neoptolemos JP, Stocken DD, Friess H, Bassi C, Dunn JA, Hickey H, Beger H, Fernandez-Cruz L, Dervenis C, Lacaine F, Falconi M, Pederzoli P, Pap A, et al. A randomized trial of chemoradiotherapy and chemotherapy after resection of pancreatic cancer. N Engl J Med. 2004;350:1200-10.

75 Oettle H, Neuhaus P, Hochhaus A, Hartmann JT, Gellert K, Ridwelski K, Niedergethmann M, Zulke C, Fahlke J, Arning MB, Sinn M, Hinke A, Riess H. Adjuvant chemotherapy with gemcitabine and long-term outcomes among patients with resected pancreatic cancer: the CONKO-001 randomized trial. JAMA. 2013;310:1473-81

76 Maeda A, Boku N, Fukutomi A, Kondo S, Kinoshita T, Nagino M, Uesaka K. Randomized phase III trial of adjuvant chemotherapy with gemcitabine versus S-1 in patients with resected pancreatic cancer:
Japan adjuvant study Group of Pancreatic Cancer (JASPAC-01). Jpn J Clin Oncol. 2008:38:227-9.

77 Moore MJ, Goldstein D, Hamm J, Figer A, Hecht JR, Gallinger S, Au HJ Murawa P, Walde D, Wolff RA, Campos D, Lim R, Ding K, et al. Erlotinib plus gemcitabine compared with gemcitabine alone in patients with advanced pancreatic cancer: a phase III trial of the National Cancer Institute of Canada clinical trials group. J Clin Oncol. 2007;25:1960-6.

78 Von Hoff DD, Ervin T, Arena FP, Chiorean EG, Infante J, Moore M, Seay T, Tjulandin SA, Ma WW, Saleh MN, Harris M, Reni M, Dowden S, et al. Increased survival in pancreatic cancer with nab-paclitaxel plus gemcitabine. N Engl J Med. 2013;369:1691-703.

79 Conroy T, Desseigne F, Ychou M, Bouche O, Guimbaud R, Becouarn Y, Adenis A, Raoul JL, Gourgou-Bourgade S, de la Fouchardiere C, Bennouna J, Bachet JB, Khemissa-Akouz F, et al. FOLFIRINOX versus gemcitabine for metastatic pancreatic cancer. N Engl J Med. 2011;364:1817-25.

80 Crompot E, Van Damme M, Pieters K, Vermeersch M, Perez-Morga D, Mineur P, Maerevoet M, Meuleman N, Bron D, Lagneaux L, Stamatopoulos B. Extracellular vesicles of bone marrow stromal cells rescue chronic lymphocytic leukemia B-cells from apoptosis, enhance their migration and induce gene expression modifications. Haematologica. 2017;

81 Zeng AL, Yan W, Liu YW, Wang Z, Hu Q, Nie E, Zhou X, Li R, Wang XF, Jiang T, You YP. Tumour exosomes from cells harbouring PTPRZ1-MET fusion contribute to a malignant phenotype and temozolomide chemoresistance in glioblastoma. Oncogene. 2017;

82 Lobb RJ, van Amerongen R, Wiegmans A, Ham S, Larsen JE, Moller A. Exosomes derived from mesenchymal non-small cell lung cancer cells promote chemoresistance. Int J Cancer. 2017;141:614-20.

83 Zheng P, Chen L, Yuan X, Luo Q, Liu Y, Xie G, Ma Y, Shen L. Exosomal transfer of tumor-associated macrophage-derived miR-21 confers cisplatin resistance in gastric cancer cells. J Exp Clin Cancer Res. 2017;36:53.

84 Ning K, Wang T, Sun X, Zhang P, Chen Y, Jin J, Hua D. UCH-L1-containing exosomes mediate chemotherapeutic resistance transfer in breast cancer. J Surg Oncol. 2017;115:932-40.

85 Au Yeung CL, Co NN, Tsuruga T, Yeung TL, Kwan SY, Leung CS, Li Y, Lu ES, Kwan K, Wong KK, Schmandt R, Lu KH, Mok SC. Exosomal transfer of stroma-derived miR21 confers paclitaxel resistance in ovarian cancer cells through targeting APAF1. Nat Commun. 2016;7:11150.

86 Wang X, Xu C, Hua Y, Sun L, Cheng K, Jia Z, Han Y, Dong J, Cui Y, Yang Z. Exosomes play an important role in the process of psoralen reverse multidrug resistance of breast cancer. J Exp Clin Cancer Res. 2016;35:186

87 Kreger BT, Johansen ER, Cerione RA, Antonyak MA. The enrichment of Survivin in exosomes from breast cancer cells treated with paclitaxel promotes cell survival and Chemoresistance. Cancers (Basel). 2016;8:1-14.

88 Patel GK, Khan MA, Bhardwaj A, Srivastava SK, Zubair H, Patton MC, Singh S, Khushman M, Singh AP. Exosomes confer chemoresistance to pancreatic cancer cells by promoting ROS detoxification and miR-155-mediated suppression of key gemcitabine-metabolising enzyme, DCK. Br J Cancer. 2017;116:609-19.

89 Santos JC, Ribeiro ML, Sarian LO, Ortega MM, Derchain SF. Exosomesmediate microRNAs transfer in breast cancer chemoresistance regulation. Am J Cancer Res. 2016;6:2129-39.

90 Namba T, Kodama R, Moritomo S, Hoshino T, Mizushima T. Zidovudine, an anti-viral drug, resensitizes gemcitabine-resistant pancreatic cancer cells to gemcitabine by inhibition of the Akt-GSK3beta-snail pathway. Cell Death Dis. 2015;6:e1795.

91 Khorana AA, Mangu PB, Berlin J, Engebretson A, Hong TS, Maitra A, Mohile SG, Mumber M, Schulick R, Shapiro M, Urba S, Zeh HJ, Katz MH. Potentially curable pancreatic cancer: American Society of Clinical Oncology clinical practice guideline. J Clin Oncol. 2016;34:2541-56.

92 Zhan HX, JW X, Wu D, Zhang TP, Pancreatic HSY. Cancer stem cells: new insight into a stubborn disease. Cancer Lett. 2015;357:429-37.

93 Egawa S, Toma H, Ohigashi H, Okusaka T, Nakao A, Hatori T, Maguchi H, Yanagisawa A, Tanaka M. Japan pancreatic cancer registry; 30th year anniversary: Japan pancreas society. Pancreas. 2012;41:985-92.

94 Poruk KE, Firpo MA, Adler DG, Mulvihill SJ. Screening for pancreatic cancer: why, how, and who? Ann Surg. 2013;257:17-26.

95 Goonetilleke KS, Siriwardena AK. Systematic review of carbohydrate antigen (CA 19-9) as a biochemical marker in the diagnosis of pancreatic cancer. Eur J Surg Oncol. 2007:33:266-70.

96 Ciardiello C, Cavallini L, Spinelli C, Yang J, Reis-Sobreiro M, de Candia P, Minciacchi VR, Di Vizio D. Focus on extracellular vesicles: new Frontiers of cell-to-cell communication in cancer. Int J Mol Sci. 2016;17:175. 
97 Erb U, Zoller M. Progress and potential of exosome analysis for early pancreatic cancer detection. Expert Rev Mol Diagn. 2016;16:757-67.

98 Que R, Ding G, Chen J, Cao L. Analysis of serum exosomal microRNAs and clinicopathologic features of patients with pancreatic adenocarcinoma. World J Surg Oncol. 2013;11:219.

99 Taller D, Richards K, Slouka Z, Senapati S, Hill R, Go DB, Chang HC. On-chip surface acoustic wave lysis and ion-exchange nanomembrane detection of exosomal RNA for pancreatic cancer study and diagnosis. Lab Chip. 2015;15: 1656-66.

100 Joshi GK, Deitz-McElyea S, Liyanage T, Lawrence K, Mali S, Sardar R, Korc M. Label-free Nanoplasmonic-based short noncoding RNA sensing at Attomolar concentrations allows for quantitative and highly specific assay of MicroRNA10b in biological fluids and circulating exosomes. ACS Nano. 2015;9:11075-89.

101 Melo SA, Luecke LB, Kahlert C, Fernandez AF, Gammon ST, Kaye J, LeBleu VS, Mittendorf EA, Weitz J, Rahbari N, Reissfelder C, Pilarsky C, Fraga MF, et al. Glypican-1 identifies cancer exosomes and detects early pancreatic cancer. Nature. 2015;523:177-82.

102 Lai X, Wang M, McElyea SD, Sherman S, House M, Korc MA. microRNA signature in circulating exosomes is superior to exosomal glypican-1 levels for diagnosing pancreatic cancer. Cancer Lett. 2017;393:86-93.

103 Madhavan B, Yue S, Galli U, Rana S, Gross W, Muller M, Giese NA, Kalthoff H, Becker T, Buchler MW, Zoller M. Combined evaluation of a panel of protein and miRNA serum-exosome biomarkers for pancreatic cancer diagnosis increases sensitivity and specificity. Int J Cancer. 2015;136:2616-27.

104 Bahn JH, Zhang Q, Li F, Chan TM, Lin X, Kim Y, Wong DT, Xiao X. The landscape of microRNA, Piwi-interacting RNA, and circular RNA in human saliva. Clin Chem. 2015;61:221-30.

105 Machida T, Tomofuji T, Maruyama T, Yoneda T, Ekuni D, Azuma T, Miyai H, Mizuno H, Kato H, Tsutsumi K, Uchida D, Takaki A, Okada H, et al. miR1246 and miR4644 in salivary exosome as potential biomarkers for pancreatobiliary tract cancer. Oncol Rep. 2016;36:2375-81.

106 Lau C, Kim Y, Chia D, Spielmann N, Eibl G, Elashoff D, Wei F, Lin YL, Moro A, Grogan T, Chiang S, Feinstein E, Schafer C, et al. Role of pancreatic cancerderived exosomes in salivary biomarker development. J Biol Chem. 2013; 288:26888-97.

107 Kanwar SS, Dunlay CJ, Simeone DM, Nagrath S. Microfluidic device (ExoChip) for on-chip isolation, quantification and characterization of circulating exosomes. Lab Chip. 2014;14:1891-900.

108 Tkach M, Kowal J, Zucchetti AE, Enserink L, Jouve M, Lankar D, Saitakis M, Martin-Jaular L, Thery C. Qualitative differences in T-cell activation by dendritic cell-derived extracellular vesicle subtypes. EMBO J. 2017;36(20): 3012-28.

109 Chen W, Wang J, Shao C, Liu S, Yu Y, Wang Q, Cao X. Efficient induction of antitumor $T$ cell immunity by exosomes derived from heat-shocked lymphoma cells. Eur J Immunol. 2006;36:1598-607.

110 Rao Q, Zuo B, Lu Z, Gao X, You A, Wu C, Du Z, Yin H. Tumor-derived exosomes elicit tumor suppression in murine hepatocellular carcinoma models and humans in vitro. Hepatology. 2016;64:456-72.

111 Dai S, Wei D, Wu Z, Zhou X, Wei X, Huang H, Li G, Phase I. Clinical trial of autologous ascites-derived exosomes combined with GM-CSF for colorectal cancer. Mol Ther. 2008;16:782-90.

112 Morse MA, Garst J, Osada T, Khan S, Hobeika A, Clay TM, Valente N, Shreeniwas R, Sutton MA, Delcayre A, Hsu DH, Le Pecq JB, Lyerly HKA Phase I study of dexosome immunotherapy in patients with advanced nonsmall cell lung cancer. J Transl Med. 2005;3:9.

113 Johnsen KB, Gudbergsson JM, Skov MN, Pilgaard L, Moos T, Duroux M. A comprehensive overview of exosomes as drug delivery vehicles endogenous nanocarriers for targeted cancer therapy. Biochim Biophys Acta. 1846;2014:75-87.

114 Vader P, Mol EA, Pasterkamp G, Schiffelers RM. Extracellular vesicles for drug delivery. Adv Drug Deliv Rev. 2016;106:148-56

115 Pascucci L, Cocce V, Bonomi A, Ami D, Ceccarelli P, Ciusani E, Vigano L, Locatelli A, Sisto F, Doglia SM, Parati E, Bernardo ME, Muraca M, et al. Paclitaxel is incorporated by mesenchymal stromal cells and released in exosomes that inhibit in vitro tumor growth: a new approach for drug delivery. J Control Release. 2014;192:262-70.

116 Osterman CJ, Lynch JC, Leaf P, Gonda A, Ferguson Bennit HR, Griffiths D, Wall NR. Curcumin modulates pancreatic adenocarcinoma cell-derived Exosomal function. PLoS One. 2015;10:e0132845.
117 Kamerkar S, LeBleu VS, Sugimoto H, Yang S, Ruivo CF, Melo SA, Lee JJ, Kalluri R. Exosomes facilitate therapeutic targeting of oncogenic KRAS in pancreatic cancer. Nature. 2017;546:498-503.

118 Aspe JR, Diaz Osterman CJ, Jutzy JM, Deshields S, Whang S, Wall NR. Enhancement of gemcitabine sensitivity in pancreatic adenocarcinoma by novel exosome-mediated delivery of the Survivin-T34A mutant. J Extracell Vesicles. 2014;3:1-9.

119 Mahmoodzadeh Hosseini H, Ali Imani Fooladi A, Soleimanirad J, Reza Nourani M, Mahdavi M. Exosome/staphylococcal enterotoxin B, an anti tumor compound against pancreatic cancer. J buon. 2014;19:440-8.

120 Bonjoch L, Gironella M, lovanna JL. Closa D. REG3beta modifies cell tumor function by impairing extracellular vesicle uptake. Sci Rep. 2017;7:3143.

\section{Submit your next manuscript to BioMed Central and we will help you at every step:}

- We accept pre-submission inquiries

- Our selector tool helps you to find the most relevant journal

- We provide round the clock customer support

- Convenient online submission

- Thorough peer review

- Inclusion in PubMed and all major indexing services

- Maximum visibility for your research

Submit your manuscript at www.biomedcentral.com/submit 